\title{
Seismic hazards assessment for radioactive waste disposal sites in regions of low seismic activity
}

\author{
CLARK H. FENTON ${ }^{1,2, \star}$, JOHN ADAMS ${ }^{3}$ and STEPHEN HALCHUK ${ }^{3}$ \\ ${ }^{1}$ Seismic Hazards Branch, URS Corporation, 500 12th Street, Oakland, CA 94607, USA \\ ${ }^{2}$ Present Address: Department of Civil and Environmental Engineering, Imperial College \\ London, London SW7 2AZ, United Kingdom.e-mail: c.fenton@imperial.ac.uk \\ ${ }^{3}$ Geological Survey of Canada, 7 Observatory Crescent, Ottawa, Ontario, Canada, K1A 0Y3. \\ e-mail:adams@seismo.nrcan.gc.ca
}

(Received 30 June 2004; revised 21 December 2004; accepted 18 January 2005)

\begin{abstract}
A comparative tectonic quiescence and lack of earthquakes make the stable centres of continents attractive for siting long-term radioactive waste storage facilities. The low rates of deformation in such regions, however, make it difficult to characterize their long-term seismotectonic behaviour, leading to uncertain estimates for the very low probability hazard estimates required by society. In an attempt to overcome the deficiency of both contemporary seismicity and paleoseismic data in central Canada, we have used earthquake histories from regions with similar seismotectonic characteristics from around the world. Substituting space for time, we estimate a long-term rate per $10^{6} \mathrm{~km}^{2}$ of 0.004 magnitude $\geq 6$ earthquakes per annum, of which $33-100 \%$ might rupture to the surface.
\end{abstract}

Key words. earthquake, radioactive waste, seismic hazard, stable craton, surface rupture.

\section{Introduction}

Away from current and recent plate boundaries, the Earth's continental plates exhibit a low rate of seismicity (Johnston et al., 1994), and the old cratons at the core of the continents have the lowest rates of seismic activity of any part of the Earth's crust. This property makes these regions attractive for the siting of high-level radioactive waste storage (or permanent disposal) facilities. For the purposes of this paper, we consider just these 'Stable Cratonic Core' regions (SCC) regions (Figure 1, see definition below). Although SCCs show much geological evidence for long-term stability, they are nevertheless capable of producing large, damaging earthquakes (Johnston et al., 1994), leading to the conclusion that SCCs are populated by a multitude of potentially seismogenic faults (Seeber et al., 1996), albeit each with extremely long time intervals between large earthquakes. A few of the larger SCC earthquakes have produced significant surface faulting, allowing study of the causative fault and raising the issue that a rare event might rupture through a bedrock repository. As part of the characterization studies for the siting of sensitive facilities,

\footnotetext{
${ }^{\star}$ Corresponding author: Clark H. Fenton, Department of Civil and Environmental Engineering, Imperial College London, London SW7 2AZ, United Kingdom. e-mail: c.fenton@imperial.ac.uk
} 


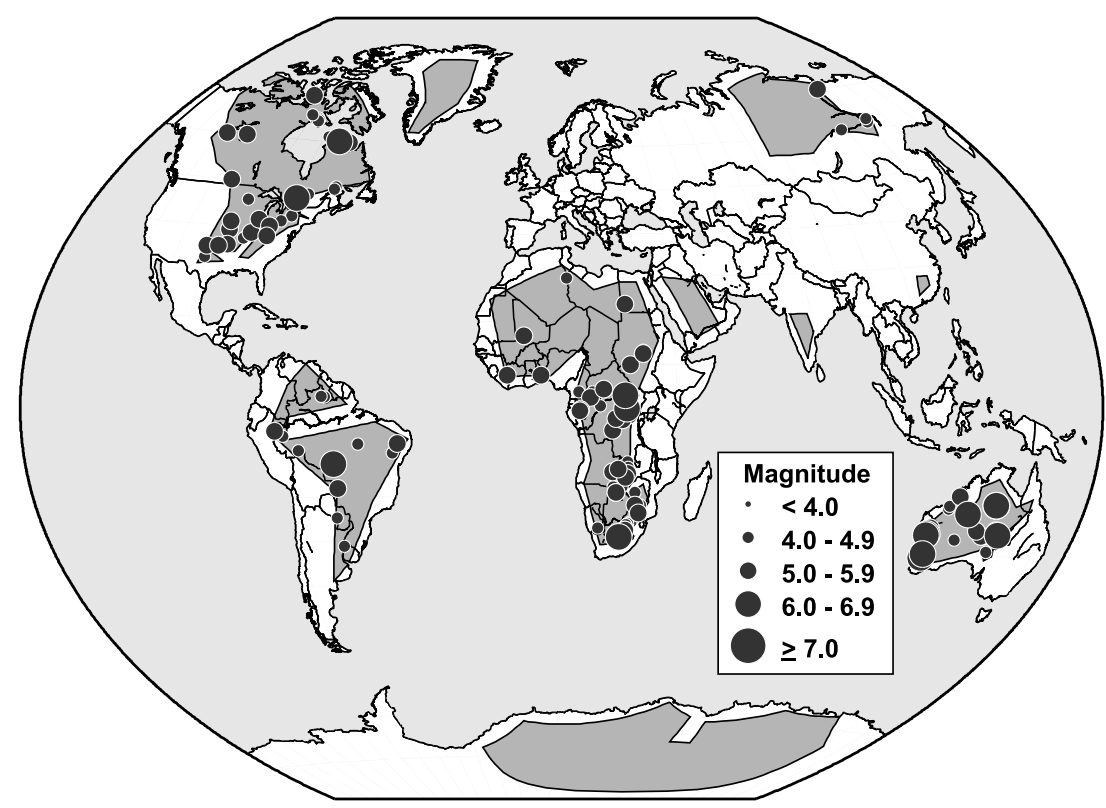

Figure 1. Worldwide distribution of Stable Cratonic Cores (SCCs are the shaded polygons) and the SCC seismicity considered to pass completeness.

such as nuclear waste repositories, it is imperative to quantify the hazard posed by these relatively rare, but potentially damaging, earthquakes.

Crone et al. (1997) show that stable continental interior regions may be characterized by faults that have long periods of quiescence, of 10,000-100,000 years or more, punctuated by brief episodes of activity. Many techniques currently employed in seismic source characterization studies were developed in, and tailored for, regions with high rates of tectonic activity (e.g., McCalpin, 1996). Fault studies using geomorphic techniques and exploratory trenching only provide useful data when the recurrence intervals for surface faulting is on the order of 100,000 years or less, thereby allowing the development of recognizable fault morphotectonic features through a history of repeated surface rupturing. Assuming that they have not ruptured recently, faults with recurrence intervals of $>100,000$ years, unless located in areas with extremely low deposition and erosion rates, will probably have no recognizable geomorphic expression. Similarly, many faults that may be capable of generating large, damaging earthquakes may never rupture to the surface (so-called 'blind' faults).

In northern latitudes, such as Canada, the United Kingdom, and Fennoscandia, many if not most geomorphic features associated with prior $(>10,000$ year old) surface faulting did not survive the erosive effects of late Pleistocene glaciations, further hampering the recognition of potentially seismogenic structures through paleoseismic structures (Adams, 1996). In addition, many phenomena active in postglacial or periglacial environments produce features that are similar to fault-related surface deformation (e.g., Adams et al., 1993; Olesen et al., 2004). 
Thus, as well as trying to identify potentially seismogenic structures, care must be taken to discard scarp-like structures produced by non-seismogenic processes from consideration in seismic source characterization studies.

In order to characterize the seismic hazard for an underground high-level radioactive waste repository in northern Ontario, a region of relatively stable Precambrian shield in eastern Canada, we used a method of statistical spatio-temporal substitution to augment incomplete geologic data and a short seismicity record. The premise of substituting space for time (also called the 'ergodic principle') requires identifying similar crustal regions around the world. This approach allows us to make a more reliable estimate of the rate of $M \geq 6$ earthquakes in northern Ontario (Note: unless otherwise specified, magnitude $(M)$ in this paper is surface-wave magnitude $M_{\mathrm{s}}$, which is approximately equivalent to moment magnitude, $M_{\mathrm{w}}$ ). Using this rate we are also able to make a statistical estimate of the potential for surface fault rupture through or near a site. This paper details the method applied and the assumptions and uncertainties involved.

\section{Seismotectonic characteristics of SCC regions}

SCCs (Figure 1) like the Canadian shield make potentially attractive sites for long-term radioactive waste storage because of their relative tectonic stability. These areas typically comprise Precambrian bedrock, generally medium- to high-grade metamorphic assemblages of silicic continental and mafic oceanic affinities. With the exception of glacio-isostatic rebound following late Pleistocene glaciation of high latitude areas, these regions have undergone little or no significant tectonism during the Phanerozoic (since $500 \mathrm{Ma}$ ). SCCs are far removed from plate boundaries, including passive margins, and contain no embedded rift structures. From experience in eastern Canada (Adams and Basham, 1991), and around the world (Johnston et al., 1994), it is clear that regions of rifted crust embedded within the continents are significantly more seismically active than adjoining unrifted regions. Rifts of Precambrian age, however, show seismic activity no higher than unrifted crust, and are assumed to be 'healed'.

We define the SCC regions as follows. We started with the 'Stable Continental Regions' defined by Johnston et al. (1994) which were the continents minus their actively-deforming regions, then removed all regions of non-Precambrian crust indicated by Johnston (1989). We further reduced the regions of Precambrian crust by excluding passive margins together with a zone of approximately $200 \mathrm{~km}$ inland from passive margin coasts and by excluding a similar $200 \mathrm{~km}$ zone around regions of Phanerozoic deformation. The remaining regions (Figure 1), with a total area of $51 \times 10^{6} \mathrm{~km}^{2}$, constitute the most stable continental regions on the planet (Figure 1). Four SCCs (Africa, North America, South America, and Australia) comprise 80\% of the total SCC area.

\section{Contemporary seismicity of northern Ontario}

Seismicity has been closely monitored in the area of northern Ontario and eastern Manitoba since 1979 (Wetmiller and Cajka, 1989). We use the local magnitude, 
$m_{\mathrm{bLg}}$, scale for contemporary seismicity in this region; $M_{\mathrm{w}}$ is approximately equal to $m_{\mathrm{bLg}}-0.5$ units. In the period up to September 1996, over 124 events, of which 26 exceeded magnitude $\left(m_{\mathrm{bLg}}\right) 3.0$, have been located in the area of Figure 2, the largest being only $m_{\mathrm{bLg}} 4.1$, in the James Bay lowlands in 1965. Historical records for this region are relatively poor, extending for only the last 100 years at most (Wetmiller and Cajka, 1989). To date, no unequivocal evidence for large magnitude surface faulting has been found in northern Ontario. We consider that given the short duration of seismic monitoring in the area and the lack of paleoseismic investigations (Fenton, 1994), it is optimistic, at best, to draw conclusions on these bases about the long-term seismotectonic stability of this area.

\section{Contemporary seismicity of SCC regions}

Each SCC region has relatively few earthquakes (Figure 1). Seismicity data for SCCs was extracted from the U.S. Geological Survey's NEIC and the EPRI (Johnston

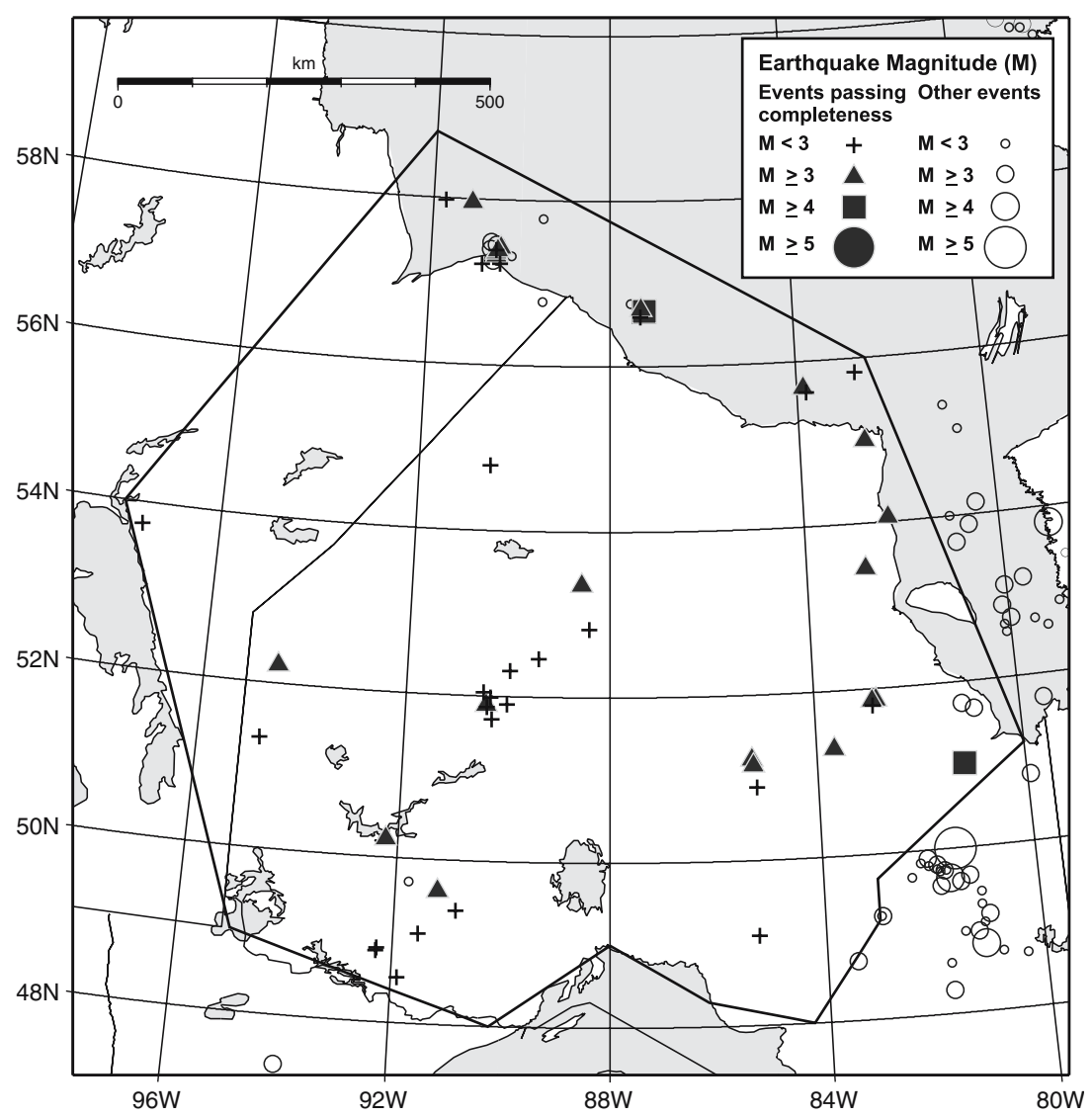

Figure 2. Contemporary seismicity in northern Ontario: all known earthquakes above $m_{\mathrm{bLg}} 2.45$. The polygon defines the SCC region considered for the magnitude-recurrence calculations. Earthquakes passing completeness are shown as solid symbols, other earthquakes as open circles. 
et al., 1994) seismicity catalogues. These data were assessed for completeness (Table 1), and corrected to remove duplicates, dependent events (aftershocks) and other spurious events including 'peaceful' nuclear explosions and mine-blasts. The processed catalogues were then used to calculate magnitude-frequency plots for each SCC (Figure 3 and Table 2) using the maximum-likelihood fitting method of Weichert (1980) which accounts for the progressive incompleteness of the historical record as we go back in time. The fitted curves are asymptotic to the 'upper bound' magnitude $\left(M_{\mathrm{x}}\right)$ for each region but have a slope $(\beta)$ for small magnitudes. Based on the worldwide data set (Johnston et al., 1994), we chose a $M_{\mathrm{x}}$ of 7.0 to cover the possibility of earthquakes as large as, or slightly exceeding, the 1988 Tennant Creek sequence of $M$ 6.4, 6.4 and 6.9 earthquakes (Crone et al., 1997). To complete the error bounds on Figures 3 and 4 we used alternative $M_{\mathrm{x}}$ of 0.2 magnitude unit higher and lower than 7.0.

Only four SCCs, - Africa, North America, South America, and Australia - had sufficient events for a statistically meaningful magnitude-frequency analysis (Figure 3). The data points and error bounds show the relatively poor quality of the South American data (Figure 3c) compared to the best individual data set, for Australia (Figure 3d). The four estimates for the rate of $M \geq 6$ earthquakes have uncertainties of 0.5 (Australia) to 1.5 (South America) orders of magnitude. The quality of these individual data sets is poor because the reliable earthquake history for each SCC is short (Table 1) and larger events are rare. Of the other five SCCs, Greenland and Antarctica, which comprise over half of the area of this subgroup, are covered by ice sheets which are believed to suppress earthquakes (Johnston, 1987), thus their low contemporary seismicity may not be representative of present-day SCC crust (nevertheless, we include their area in the calculation of the average world rate).

Our best estimate of SCC seismicity rates is made from the combined world SCC catalogue (Figure 4 and Table 2). The combined data is visibly less scattered than the individual data sets. The world SCC rate of $M \geq 6$ earthquakes is 0.18 per annum for the combined $50.7 \times 10^{6} \mathrm{~km}^{2}$ area, with the uncertainty being less than a factor of 2. Assuming that we have chosen regions that have comparable geological and

Table 1. Earthquake catalogue completeness estimates used for recurrence rate calculations for SCC regions and northern Ontario

\begin{tabular}{lllll}
\hline \multicolumn{2}{l}{ Worldwide stable cratonic cores } & & \multicolumn{2}{l}{ Northern Ontario } \\
\cline { 5 - 5 } Magnitude $\left(M_{\mathrm{s}}\right)$ range & Time period & & Magnitude $\left(m_{\mathrm{bLg}}\right)$ range & Time period \\
\hline $4.85-5.24$ & 1964-Present & & $2.45-2.94$ & 1982-Sept. 1996 \\
$5.25-5.74$ & 1950-Present & & $2.95-3.44$ & 1979-Sept. 1996 \\
$5.75-6.24$ & 1937-Present & & $3.45-3.94$ & 1963-Sept. 1996 \\
$6.25-6.74$ & 1930-Present & & $3.95-4.44$ & $1937-$ Sept. 1996 \\
$>6.75$ & 1920-Present & & $4.45-4.94$ & 1937-Sept. 1996 \\
& & & $4.95-5.44$ & 1920-Sept. 1996 \\
& & $>5.45$ & $1870-$ Sept. 1996 \\
\hline
\end{tabular}



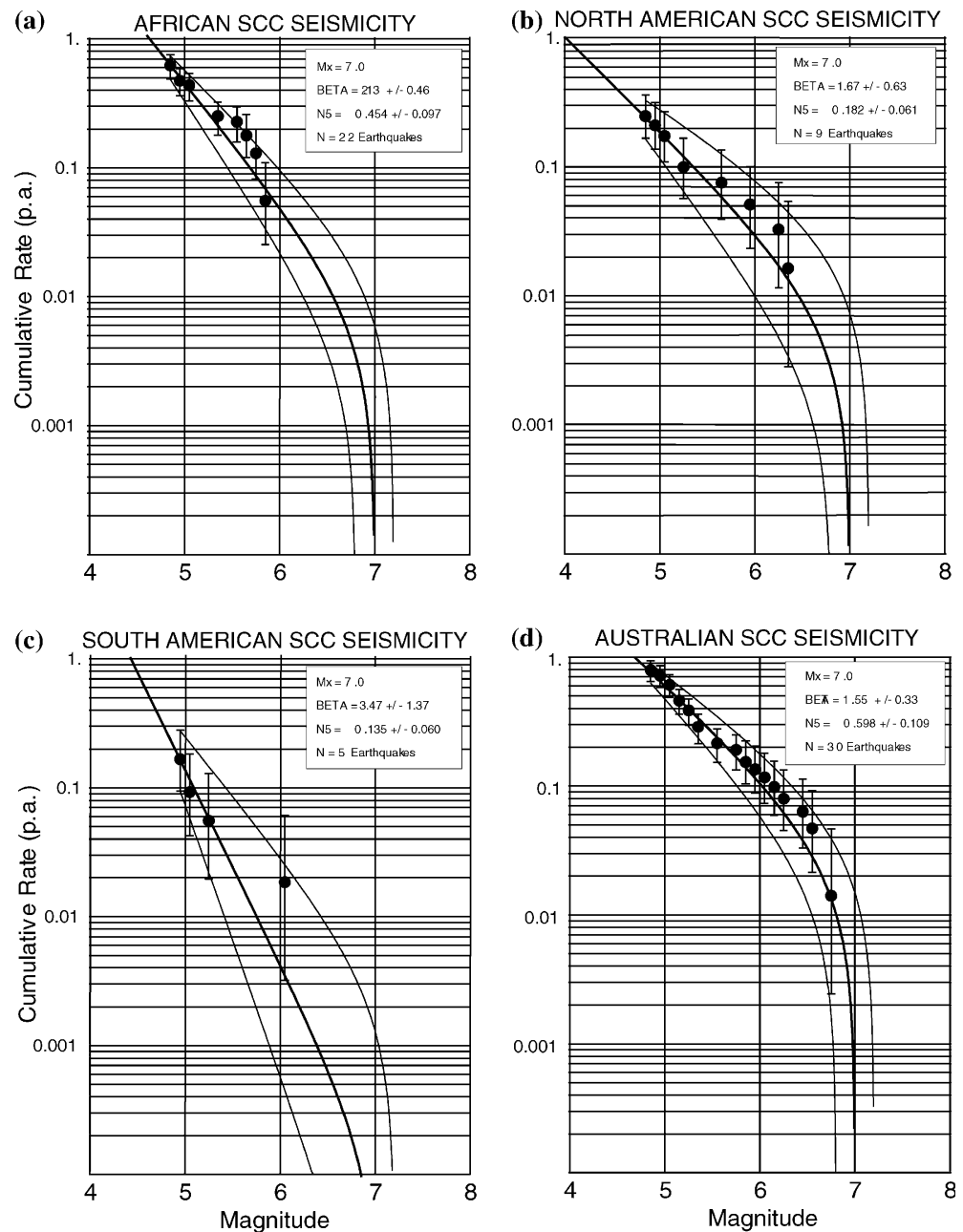

Figure 3. Magnitude-frequency plots for SCCs. (a) Africa, (b) North America, (c) South America, and (d) Australia.

seismological characteristics to northern Ontario, the world SCC seismicity rate ( $0.004 M \geq 6$ per annum per $10^{6} \mathrm{~km}^{2}$ ) provides us with our best estimate for the long-term seismic behaviour of any subset of it, and of northern Ontario in particular. We consider it should be taken as a defacto lower limit for any on-land seismic hazard assessment (including non-SCC regions).

Turning to the available seismicity data for northern Ontario, the magnitude-frequency plot (lower solid line with data points on Figure 5) is well defined for small earthquakes but lacks data on the rate of recurrence of larger events. We need to extrapolate rates by $2 \frac{1}{2}$ orders of magnitude to estimate the rate of $M \geq 6$ earthquakes as 0.0001 per annum (lower open circle at $M=6$ ). The uncertainties involved in such an extrapolation, however, are considerable since the 
Table 2. Worldwide rates of stable cratonic core seismicity

\begin{tabular}{|c|c|c|c|c|c|c|}
\hline Region & Area $\left(10^{6} \mathrm{~km}^{2}\right)$ & $\begin{array}{l}\text { Number of } \\
\text { earthquakes } \\
\text { passing completeness }\end{array}$ & Beta & $\begin{array}{l}\text { Beta } \\
\text { error }\end{array}$ & $\begin{array}{l}\text { Cumulative } \\
\text { rate } \geq M 4.9 \\
\left(10^{6} \mathrm{~km}^{-2} \mathrm{yr}^{-1}\right)\end{array}$ & $\begin{array}{l}\text { Cumulative } \\
\text { rate } \geq M 6.0 \\
\left(10^{6} \mathrm{~km}^{-2} \mathrm{yr}^{-1}\right)\end{array}$ \\
\hline Africa & 17.3 & 22 & 2.13 & 0.45 & 0.0262 & 0.0029 \\
\hline N. America & 10.7 & 9 & 1.67 & 0.63 & 0.017 & 0.0028 \\
\hline S. America & 7.7 & 5 & 3.47 & 1.37 & 0.018 & 0.0005 \\
\hline Australia & 3.5 & 30 & 1.55 & 0.33 & 0.171 & 0.031 \\
\hline Antarctica & 6.3 & 0 & $\mathrm{NC}$ & $\mathrm{NC}$ & 0.0 & 0.0 \\
\hline Siberia & 2.7 & 0 & $\mathrm{NC}$ & $\mathrm{NC}$ & 0.0 & 0.0 \\
\hline Arabia & 1.2 & 0 & $\mathrm{NC}$ & $\mathrm{NC}$ & 0.0 & 0.0 \\
\hline Greenland & 0.9 & 0 & $\mathrm{NC}$ & $\mathrm{NC}$ & 0.0 & 0.0 \\
\hline India & 0.4 & 0 & $\mathrm{NC}$ & $\mathrm{NC}$ & 0.0 & 0.0 \\
\hline World & 50.7 & 66 & 1.84 & 0.24 & 0.026 & 0.004 \\
\hline
\end{tabular}

NC: Not calculated (insufficient events $\geq$ M4.9 since 1964).

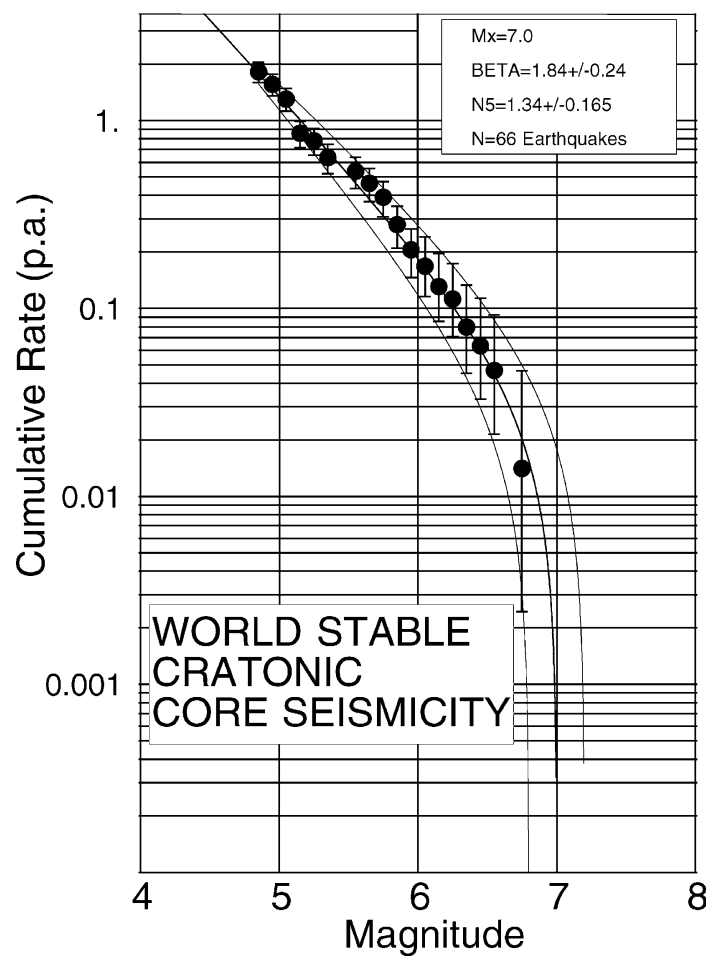

Figure 4. Magnitude-frequency (per $50.7 \times 10^{6} \mathrm{~km}^{2}$ ) plot for the worldwide SCC seismicity data set.

slope of the fitted relationship is dependent on the representiveness of the data set for moderate magnitude earthquakes. The completeness periods for earthquakes in northern Ontario are very short (Table 1), and therefore the recorded seismicity 


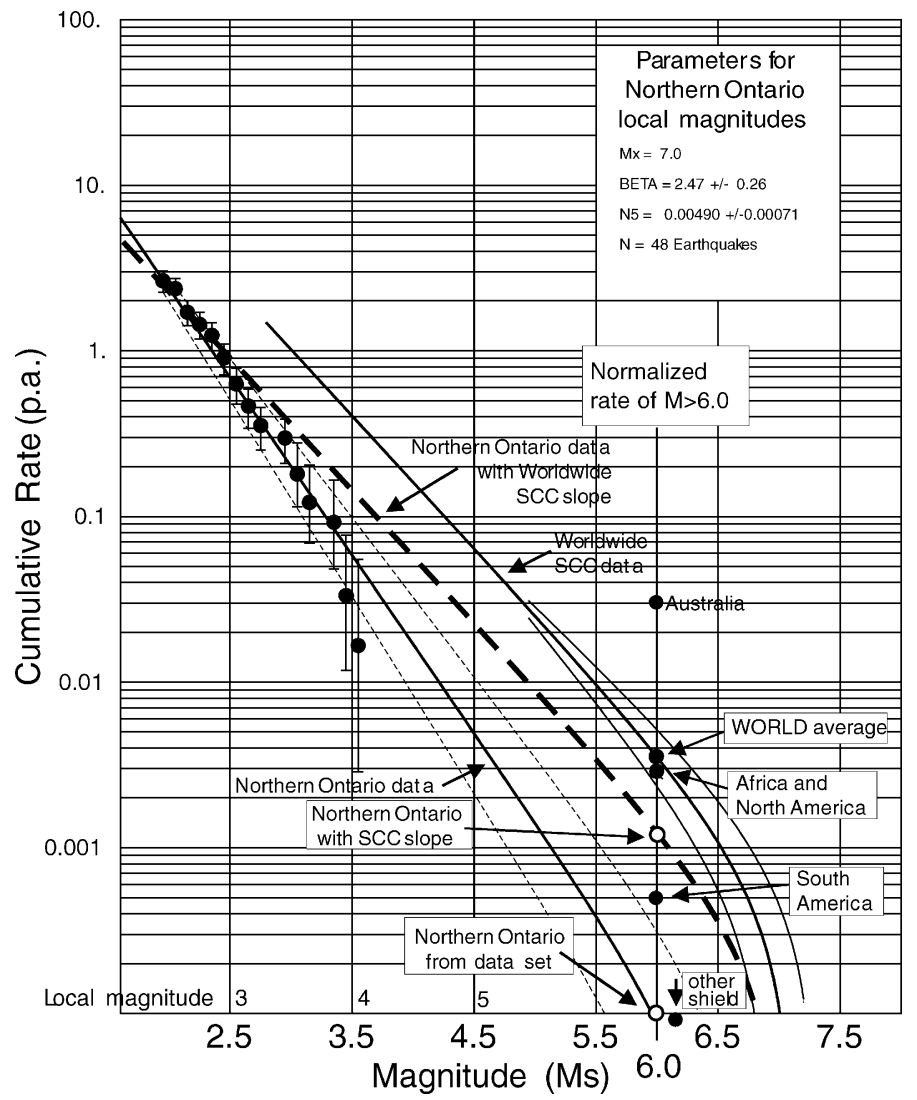

Figure 5. Magnitude-frequency plot for contemporary seismicity in northern Ontario. Note the local magnitudes $\left(m_{\mathrm{bLg}}\right)$ have been adjusted to $M_{\mathrm{s}}$ by subtracting 0.5 magnitude units. The heavy dashed line represents the worldwide SCC data set slope fitted to the rate of small earthquakes in northern Ontario. The upper solid line is the worldwide curve from Figure 4 adjusted to account for the smaller area of northern Ontario. Thin lines represent error estimates. The normalised rates of $M \geq 6$ for individual SCCs (solid dots on the vertical line at magnitude 6) are also shown.

need not be statistically representative of the longer-term rates. An alternative method of using the locally-recorded earthquakes to estimate the rate of $M \geq 6$ earthquakes in northern Ontario is by imposing the slope from the worldwide SCC data set (Figure 4) onto the rate of small earthquakes in northern Ontario. The logic is that this slope is a global parameter, and that much steeper slopes, like that of northern Ontario, are due to spatial selection (i.e., the human tendency to 'explain' and exclude active seismicity clusters) and/or statistical variability. This fit (dashed line on Figure 5) seems plausible for northern Ontario if a slight deficit of moderate earthquakes is assumed. The imposed slope together with the rate of small earthquakes gives an annual recurrence of 0.0012 for $M \geq 6$ (upper open circle at $M=6$ ). This is ten-fold greater than the 0.0001 per annum rate calculated directly from the local seismicity, but it is still somewhat less than the 0.004 per 
annum rate for the worldwide data set (Figure 5), which remains our preferred estimate for northern Ontario.

Using the worldwide rate suggests that northern Ontario (approximate area $10^{6} \mathrm{~km}^{2}$ ) has experienced between 20 and $40 M \geq 6$ events during the Holocene (the last 10,000 years). The individual SCC rates (Table 2 and Figure 5) give some idea of the uncertainty of this estimate. Note that our preferred 'world average' rate for $M \geq 6$ is 10 to 30 times greater than a conventional analysis of contemporary seismicity (i.e., lower solid line on Figure 5) would estimate. The worldwide SCC rate in this paper has been used as a basis for establishing probabilistic seismic hazard for central Canada (Adams and Halchuk, 2003), and the hazard results will be incorporated into the next edition of the National Building Code of Canada.

\section{Surface faulting hazard}

A fault rupture through an underground repository would constitute a serious ground-shaking hazard and a direct threat to the integrity of waste isolation measures. Fortunately, this is a statistically improbable event, given the very low rate of seismicity to be expected, although the statistical rate may not be appropriate once excavation is begun (see later). However, fault rupture near a repository is much more likely and would probably cause considerable changes in the local hydrogeologic regime (e.g., Muir Wood and King, 1993), which may invalidate the very long travel times computed for waste-contaminated water to reach the surface and that have been used to demonstrate the long-term isolation of the repository's radionuclides. In addition to quantifying the shaking hazard, it is therefore of great importance to estimate the likelihood of fault rupture through or near a proposed repository site.

Worldwide, eleven historical earthquakes in stable intraplate regions have produced surface ruptures (McCue et al., 1987; Adams et al., 1991; Johnston et al., 1994; Crone et al., 1997). While not all have occurred in geological settings analogous to northern Ontario, a significant number have occurred in regions of Precambrian shield areas not previously considered at risk from large, damaging earthquakes. To date, no 'active' fault has been identified in northern Ontario. The overall rate of seismicity, however, should be proportional to the number of faults times the average rate of seismicity on the individual faults. Since the slip rates of the few identified 'active' faults in intraplate environments is so low (Crone et al., 1997), the identified faults alone cannot account for the observed rates of seismicity. This discrepancy suggests that there are many 'active' faults awaiting discovery in SCC regions and that future damaging earthquakes will occur on faults not identified as being 'active'. Clearly, in SCC regions where there are numerous fault sets, only a fraction of which are exposed at the surface, it is not feasible to characterize the seismic potential of every fault. Such an 'identify and avoid' (deterministic) approach would unduly bias our hazard evaluations, placing undue emphasis on the few known seismic sources, while ignoring all the unknown potentially-active faults. 
What is, therefore, the annual probability of a future surface-faulting earthquake in northern Ontario? From worldwide SCC experience, there have been six surface rupturing earthquakes in SCCs (five in Australia in 1968, 1970, 1979, 1986, and 1988, and one in Canada in 1989). Assuming this is a complete data set, this would indicate that surface rupture is associated with events of $M \geq 6$. Alternatively, we can estimate the probability of surface rupture by considering a uniform distribution of vertical to steeply-dipping reverse faults throughout a $30 \mathrm{~km}$ thick seismogenic continental crust. According to statistical relations in Wells and Coppersmith (1994), a $M=6$ earthquake would have a rupture area of $77 \mathrm{~km}^{2}$, and a surface rupture from a $M=6$ earthquake would be $8 \mathrm{~km}$ long. These relations would indicate a fault width of $9 \mathrm{~km}$ (for comparison, the M6.3 1989 Ungava earthquake had a $10-\mathrm{km}$-long rupture and a fault width of about $5 \mathrm{~km}$ ), but in our view more realistic source dimensions have length greater than width, say $10 \times 7.7 \mathrm{~km}$ for the $M=6$. This fault width is a slope distance in the Earth, and for steeply-dipping $\left(60^{\circ}\right)$ reverse faults corresponds to about $7 \mathrm{~km}$ in depth extent. If the $M=6$ events are uniformly distributed through $30 \mathrm{~km}$ of seismogenic continental crust they will have a probability of $30 / 7.7=0.23$ of rupturing the surface. Larger events such as a $M=6 \frac{3}{4}$ event with rupture area of $421 \mathrm{~km}^{2}$, surface rupture length of $25 \mathrm{~km}$ (Wells and Coppersmith, 1994), and rupture width of $\sim 17 \mathrm{~km}$ would have a depth extent of about $15 \mathrm{~km}$ and a probability of $30 / 15=0.5$ of rupturing the surface. However, the rate of $M=6.75$ is only $20 \%$ that of $M=6$ earthquakes, so the combined probability for $M \geq 6$ is of the order of $0.8 \times 0.23+0.2 \times 0.5=0.28$; if the full integration were done, the probability might rise to one-third ( 0.33$)$. The value would be smaller if the faults are more gently dipping, or larger if the ruptures are more equant. Thus, the probability of surface faulting for a $M \geq 6$ event in a SCC ranges between 0.33 and 1 . Since SCC earthquakes generally tend to nucleate at shallow depths (Seeber et al., 1996), and $88 \%$ of Northern Ontario earthquakes appear to occur in the top $6 \mathrm{~km}$ of the crust (Ma, 2004), in our judgment the most likely value is close to the upper end of the range. From our preferred rate ( 0.004 per annum) of $M \geq 6$ events in northern Ontario (Figure 5), there has been an estimated 20-40 events during the Holocene (the last 10,000 years). Therefore, from our probability range of 0.33 to 1.0 , between 7 and 40 of these events should have ruptured to the surface.

What is the annual probability of a fault rupture within $x \mathrm{~km}$ of a site in northern Ontario? Using our SCC rate of 0.004 per annum for $10^{6} \mathrm{~km}^{2}$, the annual probability of a $M \geq 6$ epicentre within $10 \mathrm{~km}$ of a vault of radius $1 \mathrm{~km}$ is $0.004[\pi$ $\left.(10+1)^{2} / 10^{6}\right]=1.5 \times 10^{-6}$ (for a $20 \mathrm{~km}$ radius, the probability is four times higher). Seeber et al. (1996), using data on surface faulting from Australia and India, and assuming an annual recurrence rate of $10^{-5}$ for individual faults, calculated that there should be approximately $2 \times 10^{4}$ faults with the potential for surface rupture in these two regions. They considered this value to be a minimum. Normalised to the approximately $10^{6} \mathrm{~km}^{2}$ area of northern Ontario, this implies approximately 500 potential surface rupturing faults, and for a random fault distribution, this suggests 
approximately one fault approximately every $2000 \mathrm{~km}^{2}$. The probability of one of these faults lying within $10 \mathrm{~km}$ of any repository site is $\left(\pi \times 11^{2}\right) / 2000=0.19$. Because a 100,000 year return period for surface faulting on an individual fault was assumed, the Seeber et al. (1996) analysis indicates a $2 \times 10^{-6}$ annual probability (or higher) of surface faulting within $10 \mathrm{~km}$ of the site, consistent with our analysis if a large fraction of $M \geq 6$ events are surface rupturing. The probability of a fault rupture within $20 \mathrm{~km}$ of the repository site is 0.69 , which gives an annual probability of surface rupture of $7 \times 10^{-6}$.

To date, no evidence for a surface rupture has been found in northern Ontario. When we consider the rather subdued surface rupture of the 1989 M 6.3 Ungava earthquake (Adams et al., 1991, 1992), and the low effort expended on fault-specific searches, this does not seem surprising, since many surface-rupture features would likely disappear, through revegetation, slopewash, periglacial, and other processes, relatively quickly - decades to centuries - relative to the ca. 100,000 year recurrence interval for surface-rupturing events (Fenton, 1999). This raises the concern that potentially active faults may be numerous in SCCs and that their presence may be undetected, nay undetectable, prior to their next surface-rupturing event.

\section{Discussion}

Regions of low to moderate seismic activity, far removed from active plate margins, often have had long and complex geologic histories. They are cut by a number of fault sets, some of which may have been reactivated during several tectonic episodes. Any of these faults may have the potential to be reactivated during $M \geq 6$ earthquakes. In a deterministic seismic hazards assessment each potentially seismogenic structure (i.e., faults that have moved recently, and those that may move in the geologically-near future) must be identified and characterized (when did they move, how often do they move, and how large are the earthquakes?). This is problematic since: (1) faults as short as $5 \mathrm{~km}$ are capable of producing damaging earthquakes; (2) faults dismissed as 'inactive' may experience rupture; and (3) even if all surface active faults are identified, the problem of blind seismogenic sources remains. Thus, for intraplate regions, we consider hazard-elimination approaches that advocate an 'identify and avoid' approach to active faults to be of dubious value.

We consider that most, if not all, future large earthquakes will occur on existing faults, so that for a suitably important site careful investigations of all nearby faults are essential. Such investigations together with sound judgment will tend to improve the odds that a site safer than the 'average' SCC is chosen. However, while such studies might increase the decision-maker's comfort level significantly with respect to a future earthquake rupturing into the repository, they might not reduce the computed shaking hazard level or induced hydrological effects very much. Of additional worry is that the 'natural' hazard, estimated for an unexcavated virgin site, might be significantly increased by the construction of the repository. This might occur by mass removal (sizable earthquakes have been triggered by surface quarrying, see 
Yerkes et al., 1983; Seeber et al., 1998), stress redistribution (many mines induce considerable seismic activity as the rockmass readjusts, and there is evidence that mining at Sudbury has triggered shear slip on faults cut by tunnels), and hydrostatic changes (during construction the hydrostatic effect of the repository would be zero to stabilizing, but after closure the slow flooding could trigger activity, as has been seen from recently flooded mines in Canada). Although they might not be quantifiable, any of these construction-related responses could trigger nearby earthquakes that otherwise might not have occurred for tens of thousands of years, and so render even the best prior hazard estimates moot.

\section{Conclusions}

Rather than relying on incomplete or random discoveries of surface faulting, statistical estimates of earthquake occurrence in SCCs can be made using carefully evaluated seismological and geological data. A reliable earthquake history, in terms of both location and magnitude, accompanied by available paleoseismic data, will provide the qualified input for a probabilistic seismic hazard model based on random events within the appropriate source zone. It is important that these data are assessed qualitatively for completeness and accuracy. In addition, these data must be gathered from a geologically uniform region that is large enough to provide statistically meaningful rates. Such an approach, based on sound expert judgment, should produce hazard estimates that are defensible and will not have to be automatically adjusted if (or when) new evidence for coseismic rupture is found nearby the site of concern. By using this approach, we have used the combined earthquake history of continental regions with a similar geologic setting and history to the craton of eastern Canada to constrain the expected rates of large earthquakes and the likelihood that they will rupture to the surface.

\section{Acknowledgements}

This paper is developed from our written contribution to the Proceedings of the 3rd European Engineering Geology Conference 'Geo-engineering of hazardous \& radioactive waste disposal' held in Newcastle, United Kingdom, 10-14 September 1997. We thank Arch Johnston, Ganpat Lodha, Anton Brown, and Gail Atkinson for discussions back in the 1990s and the two anonymous journal referees for sharpening the arguments.

\section{References}

Adams, J. (1996) Paleoseismology in Canada: a dozen years of progress, J. Geophys. Res., 101, 6193-6207.

Adams, J. and Basham, P. (1991) The seismicity and seismotectonics of eastern Canada, In: Slemmons, D.B., Engdahl, E.R., Zoback, M.D. and Blackwell, D.D. (eds.), Geological 
Society of America Decade Map, Boulder, Colorado, Neotectonics of North America Vol. 1, pp. 261-276.

Adams, J. and Halchuk, S. (2003) Fourth generation seismic hazard maps of Canada: values for over 650 Canadian localities intended for the 2005 National Building Code of Canada. Geological Survey of Canada, Open File 4459, pp. 1-155. Also available from http:// www.seismo.nrcan.gc.ca/hazards/OF4459/

Adams, J., Percival, J.A., Wetmiller, R.J., Drysdale, J.A. and Robertson, B. (1992) Geological controls on the 1989 Ungava surface rupture: a preliminary interpretation, Current Research, Geological Survey of Canada Paper 92-1C, pp. 147-155.

Adams, J., Wetmiller, R.J., Hasegawa, H. and Drysdale, J. (1991) The first surface faulting from a historical intraplate earthquake in North America, Nature, 352, 617-619.

Adams, J., Dredge, L., Fenton, C., Grant, D.R. and Shilts, W.W. (1993) Late Quaternary faulting in the Rouge River Valley, southern Ontario: seismotectonic or glaciotectonic? Geological Survey of Canada, Open File 2652, pp. 1-60.

Crone, A.J., Machette, M.N. and Bowman, J.R. (1997) Episodic nature of earthquake activity in stable continental regions revealed by paleoseismicity studies of Australian and North American Quaternary faults. Aust. J. Earth Sci., 44, 203-214.

Fenton, C.H. (1994) Postglacial faulting in eastern Canada: an annotated bibliography, Geological Survey of Canada, Open File 2774, pp. 1-98.

Fenton, C.H. (1999) Glacio-isostatic (postglacial) faulting: Criteria for recognition, In: Hanson, K.L., Kelson, K.I., Angell, M.A. and Lettis, W.R. (eds.), Identifying Faults and Determining Their Origins, U.S. Nuclear Regulatory Commission, NUREG/CR-5503, Appendix A, pp. A-51-A-99.

Johnston, A.C. (1987) Suppression of earthquakes by large continental ice sheets, Nature, 303, 467-469.

Johnston, A.C. (1989) The seismicity of stable continental interiors, In: Gregersen, S. and Basham, P.W. (eds.), Earthquakes at North Atlantic Passive Margin: Neotectonics and Postglacial Rebound, Kluwer Academic Press, Amsterdam, pp. 299-327.

Johnston, A.C., Coppersmith, K.J., Kanter, L.R. and Cornell, C.A. (1994) The earthquakes of stable continental regions, Volume 1: Assessment of large earthquake potential, Electric Power Research Institute, Technical Report TR-102261-V1, pp. 1-368.

Ma, S. (2004) Focal Depth Investigation for earthquakes from 1980 to 2003 in Northern Ontario Using Regional Depth Phase (sPg, sPmP) Modelling (RDPM) Method and Surface Waves. Research Contract Report to Earthquakes Canada, Contract NRCan-04-0601, pp. 1-111.

McCalpin, J.P. (1996) Paleoseismology, Academic Press, San Diego.

McCue, K., Barlow, B.C., Denham, D., Jones, T., Gibson, G. and Michael-Leiba, M. (1987) Another chip off the old Australian block, EOS, Transact. Am. Geophys. Un., 68, 609-612.

Muir Wood, R. and King, G.C.P. (1993) Hydrological signatures of earthquake strain, J. Geophys. Res., 98, 22035-22068.

Olesen, O., Blikra, L.H., Braathen, A., Dehls, J.F., Olsen, L., Rise, L., Roberts, D., Riis, F., Faleide, J.I. and Anda, E. (2004) Neotectonic deformation in Norway and its implications: a review, Norw. J. Geol., 84, 3-34.

Seeber, L., Ekstrom, G. and Armbruster, J.G. (1996) The 1993 Killari earthquakes in central India: a new fault in Mesozoic basalt flows? J. Geophys. Res., 101, 8543-8560.

Seeber, L., Armbruster, J.G., Kim, W.-Y., Barstow, N., and Scharnberger, C. (1998) The 1994 Cacoosing Valley earthquakes near Reading, Pennsylvania: a shallow rupture triggered by quarry unloading, J. Geophys. Res., 103, 24505-24521.

Weichert, D.H. (1980) Estimation of the earthquake recurrence parameters for unequal observation periods for different magnitudes, Bull. Seismol. Soc. Am., 70, 1337-1346. 
Wells, D. and Coppersmith, K. (1994) New empirical relationships among magnitude, rupture length, rupture width, rupture area, and surface displacement, Bull. Seismol. Soc. Am., 84, 974-1002.

Wetmiller, R.J. and Cajka, M.G. (1989) Tectonic implications of seismic activity recorded by the northern Ontario seismograph network, Can. J. Earth Sci., 26, 376-386.

Yerkes, R.F., Ellsworth, W.L., and Tinsley, J.C. (1983) Triggered reverse faulting and earthquake due to crustal unloading, northwest Transverse Ranges, California, Geology, 11, 287-291. 